\title{
PARADIDÁTICO E EDUCAÇÃO: UMA CONVERSA INFORMAL
}

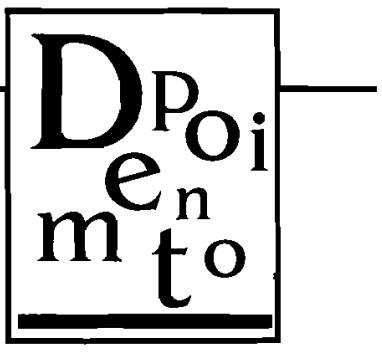

\section{Livros paradidáticos de divulgação científica ajudam a ampliar e sedimentar conhecimentos}

Como autora de livros de divulgação científica destinados ao primeiro grau, sou com frequiência convidada para fazer palestras para alunos e professores que leram meus livros. Mas, como palestras formais são cansativas, transformo esses encontros em um batepapo descontraído, no qual eu falo a respeito dos meus livros e do meu trabalho. Assim, ao ser convidada para escrever um depoimento aos professores, leitores desta revista, resolvi adotar o mesmo tom informal dessas conversas.

Uma pergunta que sempre me fazem nesses encontros é como foi que me tornei escritora de livros de divulgação científica para jovens. E eu conto que tudo começou quando eu tinha 12 anos e comecei a anotar em um caderno o que eu pensava e sentia, tudo que eu observava e acontecia em meu pequeno mundo adolescente. Foi assim que começou a nascer meu desejo de ser escritora e ele cresceu ainda mais quando ganhei uma máquina de escrever. Todos os dias eu escrevia, tanto para mim mesma como para jornais e para vários correspondentes. Com um deles, também escritor, ainda hoje me correspondo. Escrever tornou-se um hábito para mim e um desafio.

Escrever ajuda a pensar porque precisamos definir nossas idéias, escolher a seqüência em que elas devem ser apresentadas, selecionar as palavras que tornem claro o pensamento e finalmente nos colocar no lugar de quem lê para conferir se conseguimos comunicar o que pensamos e sentimos. Além de gostar de escrever, gostava de ler e isso foi fundamental para o trabalho que hoje faço. Meu gosto pela leitura seguiu a trajetória comum: histórias em quadrinhos, romances de amor e aventura, os clássicos da literatura. Depois, lendo o Tesouro da Juventude, coletânea de divulgação das ciências exatas e
A AUTORA
Rosicler Martins Rodrigues
Bíóloga, pós-graduada em Zoologia. Autora da Editora Moderna, com oito livros publicados nas áreas de saûde, antropologia, zoologia, história e comportamento. 
humanas, descobri um outro tipo de livro, com narrativa sem cnredo $e$ sem personagens, uma linguagem que vai direto ao assunto, informa e faz, pensar, cria cm nossa mente novas imagens e novas idéias. Foi então que comecei a ler para aprender fatos, fenômenos, acontecimentos, pois é através da linguagem objetiva que é transmitido o conhecimento amealhado por pesquisadores e pensadores. $E$ foi assim que entrei para o mundo dos livros, de informações e reflexões que nos levam para o passado, para as muitas regiões da Terra, nos revelam outros modos de vida e outros valores, nos carregam para o fundo dos oceanos, part a vida microscópica e o mundo invisível dos átomos, nos fazen chegar no universo dos planetas c galáxias e tambem para os pensamentos construídos através do tempo. Uma grande aventura!

\section{PRIMEIRA LXPERIÊNCIA}

Gostar de escrever e de ler encaminhou-me para o que hoje faço. Mas igualmente decisivo foi o meu amor à natureza, aos bichos e às plantas, que me levou a cstudar biologia $e$ a pesquisar a vida animal. Durante vários anos observei a natureza. Mas nem todas a paixões viram amor eterno e descobri que fazer pesquisa na área de biologia não se resume a gostar da natureza. Para desenvolver uma pesquisa científica é necessário escolher um tema em

A Crência a serviģs do conhecimento. uma área especifica, destacar o que deve ser observado, ir ao trabalho de campo, organizar as observaçóes que se fez, compará-las com as de outros pesquisadores de hoje e do passado, transformar suas observaçôes em tabelas, números, gráficos, chegar a conclusōes, redigir o trabalho em linguagem especializada para publicá-1o na forma de ama tese ou separata, para comunicar suas descobertas que serão lidas por pesquisadores da mesma área. Não gostei dessa experiênciá. Queria lex e escrever sobre muitas coisas diferentes e ser lida por maior número de pessoas. Assim, desisti da carreira de cientista.

Minha primeira experiência como escritora foi um trabalho em equipe para o desenvolvimento de um projeto de ciência integrada, que juntasse física química e biologia para contar a história da ciência e as transformaçôes que cla foi causando na vida humana desde a domesticaçăo das plantas e dos animais. Foi uma expc- 
riência que abriu as portas de áreas do conhecimento pelas quais ainda não tinha passado, como a economia e a antropologia. Depois, participei da elaboração de outros projetos ligados ao ensino de ciências, biologia e educação ambiental e ampliei ainda mais meu universo de conhecimentos e a capacidade de entrelaçar várias áreas. Na editoria das revistas Ciências para Crianças e Revista de Ensino de Ciências, onde trabalhei durante dez anos, tive a oportunidade de aproximar-me de professores e alunos do primeiro grau. Esses foram anos de preparação para os livros que hoje escrevo, para leitores de primeira a oitava séries, um público curioso, que gosta muito de ver televisão, mas também gosta de ler, quando incentivado por um bom livro e um bom professor.

Meus livros nascem do prazer de ler, de escrever, de pesquisar um assunto durante meses, do desejo de levar os jovens comigo para as aventuras do conhecimento criado por pesquisadores de várias áreas e de todos os tempos.

É um trabalho de divulgação da Ciência, que é demorado porque exige conversas com pesquisadores, leitura de suas teses e trabalhos, longas horas em livrarias e bibliotecas para encontrar livros e revistas especializadas. Só então estamos preparados para, finalmente, escrever o que queremos transmitir.

Quando a escrita é para crianças e jovens, que estão aprendendo o vocabulário científico, é preciso apurar a linguagem até ela se tornar clara, pois quando o leitor tropeça nas palavras ou nas idéias mal formuladas, não consegue entender a mensagem e desiste da leitura.

O divulgador da ciência é um tradutor dos trabalhos dos pesquisadores. Precisa traduzir sem trair as idéias originais, tendo em mente as palavras de Thoreau, que diz: "o cientista que não está procurando expressar-se, fala da natureza com uma linguagem morta".

$O$ livro de divulgação científica não deve apenas oferecer informações atualizadas em linguagem simples e até poética, quando possível. Deve também oferecer reflexões e críticas sobre o fazer da Ciência e seu papel no mundo de hoje, sobre as transformações que ela causa em nossas vidas, sobre as responsabilidades dos cientistas, sobre as contradições de nossa sociedade. Deve entrelaçar as ciências exatas e humanas. Enfim, deve fazer o leitor pensar.

Hoje, os meios de comunicação tendem a glorificar os feitos da Ciência e os cientistas, através de notícias que causam impacto, como a do camundongo com orelhas de gente ou a do último fóssil 
Explorar, con criarvidade,

que lançou novas luzes sobre as origens simiescas do homem. Quem não está minimamente informado sobre assunios cientíticos não consegue avaliar informações como essas e se toma presa da ideologia dos meios de comunicaçũo de massa.

a curiosidade da eriança

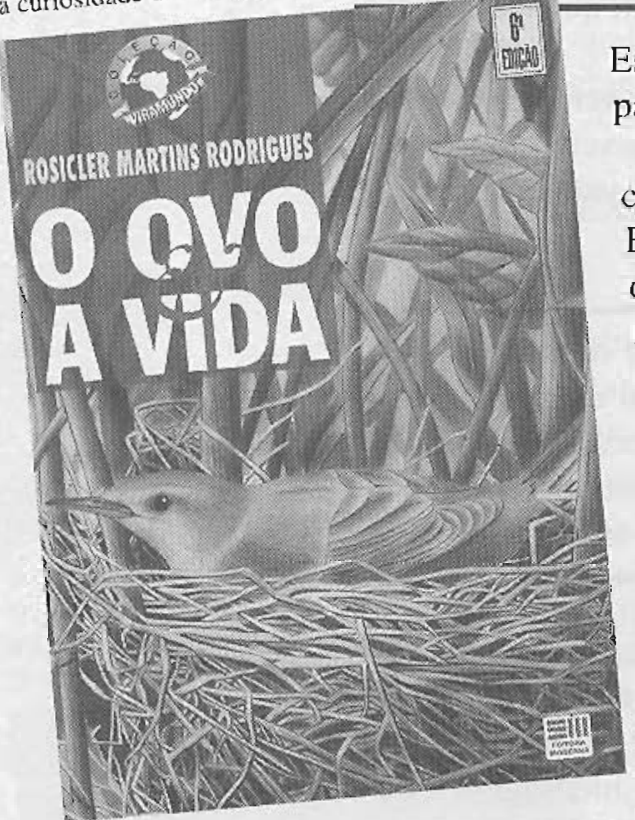

Essas devem ser algumas das finalidades dos livros paradidáticos de divulgação científica.

Os livros paradidâticos estão sendo edilados cada vez em maior número e em todas as áreas. Em muitas escolas, dividem com os livros didáticos o espaço educacional. Em outras, ocupam o lugar dos didáticos, porque estes abordam tantos temas que não conseguem se aprofundar $\mathrm{cm}$ nenhum deles. O paradidático, por não ter a preocupação de dar conta do currículo de um ano inteiro, pode trabalhar um tema em profundidade. e em vários ângulos, ligando-o a outras áreas, inserindo-o em um contexto que faz sentido para o jovem leitor. Por isso, sua leitura costuma ser mais interessante e agradável do que a do livro didático.

\section{CONSTRUIR O CONHECIMENTO}

Atualmente, passamos por uma fase renovadora da educação. Em várias escolas, públicas e particulares, os professores estão trabalhando no sentido de criar para seus alunos oportunidades que desenvolvam a capacidade de aprender a aprender. O conhecimento pronto, resumido e compactado para ser assimilado memoristicamente c devolvido em provas está sendo substituído pela construção gradativa do conhecimento através de lcituras, debates, apresentação de seminários, pesquisas na comunidade, trabalhos escritos. Nesse processo, lento mas recompensador, o livro paradidático lem desempenhado um papel importante.

Em primeiro lugar, porque traz informaçòes atualizadas e de boa qualidade. Há autores cientistas que abrem em seu tempo de trabalho um espaço para divulgar o conhecimento para os jovens. Há 
autores jornalistas, especializados em determinados assuntos. Há autores profissionais da escrita, com disponibilidade integral para se aprofundar na pesquisa do tema sobre o qual estão escrevendo.

O paradidático é um bom instrumento para o treino da leitura objetiva. Por essa razão, vejo com surpresa alguns paradidáticos de divulgação científica que recorrem à fieção para atrair os alunos. o que nem sempre acontece, porque é difícil criar uma boa ficção que distraia e informe. Além disso, é importante que o estudante aprenda a ler a escrita objetiva, pois é através dela que o conhecimento cicntífico é passado em todas as áreas.

O livro paradidático de divulgação científica, quando usado com criatividade pelos professores, não fica limitado à leitura individual dos estudantes. Após a leitura, ele se torna um ponto de partida para debates, leituras de outros livros relacionados ao tema, pesquisas em revistas, jornais e até mesmo na comunidade. $O$ aluno se torna um pesquisador.

Há pouco tempo, visitando uma escola, tive a oportunidade de ler pesquisas desenvolvidas por alunos de quinta e sexta séries, a partir de dois livros de minha autoria. Após a leitura, eles preparam pequenos projetos que foriun desenvolvidos na comunidade, abordando temas como macrobiótica, vegetarianismo, obesidade, uso de aditivos químicos na conservação dos alimentos, direitos do consumidor. uso e abuso do açúcar, hábitos alimentares, práticas do cooper e da aeróbica, poluição do ar e vários outros temas abordados nesses livros. Os professores que adotam livros paradidáticos, com frequiência solicitam a presença dos autores dos livros para conversar com os alunos. Em um país como o nosso, onde as escolas oferecen poucas atividades culturais para os jovens, esses eventos são muito importantes.

Enfim, não fossem os paradidálicos de divulgação científica, o que os cientistas estão fazendo em seus laboratorios, o conhecimento adquirido e sua ligação com a política e a cconomia mundial, que afinal acabam se refletindo na nossa vida cotidiana, ficariam restritos to que é publicado em revistas, jornais e na televisão, o que seria insuficiente para um mundo como o de hoje, no qual a ciência e a tecnologia ocupam cada vez mais espaço e precisam ser compreendidas com maior profundidade e espírito crítico.

O conhecitzont
ajuclat o honwem a defende a saúde e a viddat.

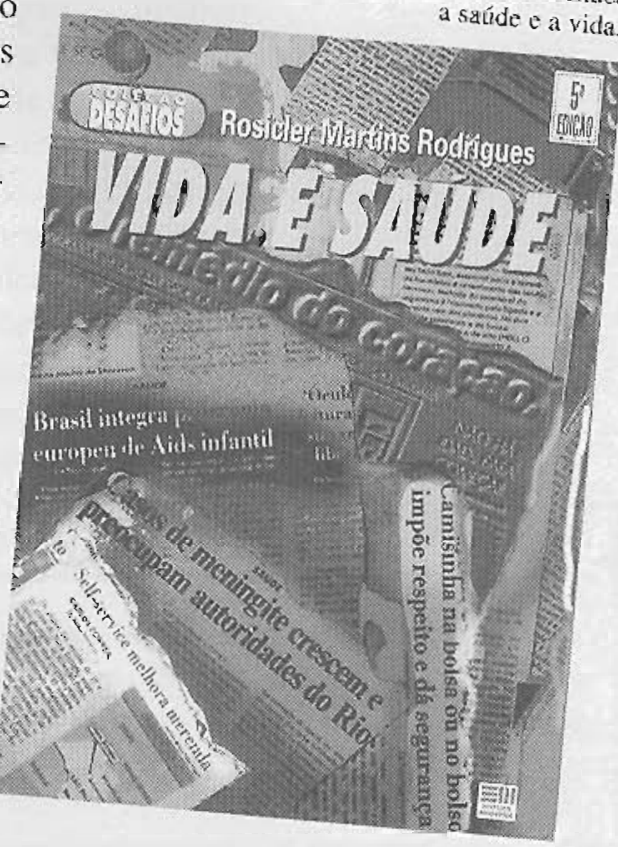


Resumo: A autora conta sua experiência pessoal enquanto autora de livros paradidáticos dirigidos a estudantes do primeiro grau. Trata da importância desse tipo de leitura de divulgação científica para que os jovens tenham autonomia e se desenvolvam enquanto pesquisadores e produtores de conhecimento.

Palavras-chave: livro paradidático, divulgaçāo científica, leitura, escola, conhecimento.

Abstract: Rosicler Martins Rodrigues tells about her personnal experience as an author of paradidactic books for students of elementary school. She deals with the importance of this kind of reading in disclosing science to make young people develop their skills as researchers.

Key-words: book, paradidactic, divulgation, scientific, school, knowledge, reading. 